Tropical Journal of Pharmaceutical Research April 2015; 14 (4): 649-653

ISSN: $1596-5996$ (print); 1596-9827 (electronic)

(C) Pharmacotherapy Group, Faculty of Pharmacy, University of Benin, Benin City, 300001 Nigeria.

All rights reserved.

Available online at http://www.tjpr.org

Original Research Article

http://dx.doi.org/10.4314/tjpr.v14i4.13

\title{
Prevalence and Antibiotic Susceptibility Pattern of E. coli Isolated from Urinary Tract Infection in Patients with Renal Failure Disease and Renal Transplant Recipients
}

\author{
Mohammad Aghazadeh1, Soyar Sari ${ }^{2}$, Mohammadreza Nahaie ${ }^{1}$, Seyed \\ Sadraddin Rasi Hashemi ${ }^{3}$ and Samaneh Mehri ${ }^{1 *}$ \\ ${ }^{1}$ Department of Bacteriology and Virology, School of Medicine; ${ }^{2}$ Department of molecular and cellular science, Faculty of \\ advanced sciences technology, Pharmaceutical sciences branch, Islamic Azad University, Tehran, Iran; ${ }^{3}$ Chronic Kidney \\ Disease Research Center, Tabriz University of Medical Sciences, IR Iran M
}

*For correspondence: Email: mehri.samaneh@gmail.com; Tel/Fax: +982144652354

Received: 11 January 2015

Revised accepted: 22 March 2015

\begin{abstract}
Purpose: To determine the common uropathogens found in patients with urinary tract infections and to assess their antibiotic susceptibility patterns.

Methods: The prevalence and antibiotic susceptibility pattern of E. coli in urinary tract infection inpatients with renal failure disease and renal transplant recipients (group 1) and in outpatients (group 2), admitted in/attending Imam Reza Hospital in Tabriz, Iran, were determined. Isolates were analyzed by standard methods, and antimicrobial susceptibility testing was performed by Kirby-Bauer disc diffusion method.

Results: A total of 136 E. coli strains from 81 females and 55 males were examined. The high level of antibiotic susceptibility for group 1 was cefuroxime/ceftazidime (100\%) and nitrofurantoin (81.63\%), respectively; and for group 2, it was ampicillin (95.83\%) and nitrofurantoin (93.75\%), respectively. Conclusion: The most important finding of this study is that a considerable proportion of the studied $E$. coli isolates are resistant to the antibiotics tested, except nitrofurantoin. This finding is useful for clinicians to determine appropriate empirical antimicrobial treatment in similar cases and would also help health authorities to formulate antibiotic prescription policies.
\end{abstract}

Keywords: Urinary tract infection, Antibiotic susceptibility pattern, Uropathogens, Renal failure, Renal transplant, Escherichia coli

Tropical Journal of Pharmaceutical Research is indexed by Science Citation Index (SciSearch), Scopus, International Pharmaceutical Abstract, Chemical Abstracts, Embase, Index Copernicus, EBSCO, African Index Medicus, JournalSeek, Journal Citation Reports/Science Edition, Directory of Open Access Journals (DOAJ), African Journal Online, Bioline International, Open-J-Gate and Pharmacy Abstracts

\section{INTRODUCTION}

Escherichia coli (E. coli) is one of the most important causes of community-acquired and nosocomial infections. This organism is therefore of clinical importance and can be isolated from various clinical specimens [1]. Urinary tract infections (UTIs), including cystitis and pyelonephritis, are the most common infectious diseases in childhood. E. coli accounts for as much as $90 \%$ of the community-acquired and 50 $\%$ of the nosocomial UTIs $[2,3]$.

Knowledge of antimicrobial resistance pattern in $E$. coli, the predominant pathogen associated with urinary tract infection is important as a guide in selecting empirical antimicrobial therapy. Microbial infections are one of the major problems militating against successful organ transplantation and can cause high morbidity and mortality among transplant recipients. Infections 
in renal transplant recipients account for $26 \%$ of hospitalization days annually and $40 \%$ of overall mortalities [4]. Although UTI is one of the most common bacterial diseases in children, its diagnosis is often delayed due to obscure clinical findings. In pediatric patients, acute pyelonephritis may be associated with high morbidity and long-term complications like renal scarring, hypertension, and chronic renal failure [5-7].

Gram-negative enteric bacilli, especially $E$. coli and Klebsiella spp., are the leading pathogens, though Enterococcus spp., yeasts, and Staphylococcus spp. have recently emerged as prominent agents [5]. Worldwide, 150 million people are diagnosed with UTI each year, costing the global economy in excess of US\$ 6 billion [8]. In the United States, surveys have estimated an incidence of 8 million UTI episodes per year [9]. A study from Turkey showed that $17.8 \%$ of all visits were patients with UTI at primary care settings [10].

The predominance of Gram-negative species, usually Enterobacteriaceae and, particularly, Escherichia coli, remained the principal pathogens causing UTI, accounting for 75 - 90 $\%$ of all urinary tract infections in both inpatients and outpatients [11]. The in vitro susceptibility of E. coli urinary isolates to the most common antimicrobial agents used for the treatment of patients with UTI varies considerably in different parts of the world [12-14]. Antibiotics are usually given empirically before laboratory results from urine culture are available. To optimize the use of empirical antibiotic therapy for UTI, it is important for clinicians to be aware of the etiological agents and susceptibility patterns of UTI pathogens in their populations. Hence, various centers consider the results of urine culture previously obtained from their microbiology laboratory in selecting empirical antibiotic treatment for UTI [15].

The aim of this study was to investigate microbial species isolated from patients with UTI and evaluate $E$. coli prevalence and antibiotic susceptibility pattern in patients with renal failure disease and renal transplant recipients hospitalized in Imam Reza Hospital, Tabriz, Iran.

\section{EXPERIMENTAL}

\section{Specimen collection}

Urinary specimens were obtained from renal failure transplant and failure patients and outpatients. For each patient, age, sex, collection date, prescribed antibiotic and hospitalization period was registered.

Ten $\mathrm{ml}$ of midstream clean urine specimens were collected in sterile containers and transported to the laboratory in minimum time for analysis and culturing on appropriate bacteriologic media [16].

\section{Macroscopic and microscopic examination}

For macroscopic examination color and appearance of collected urine samples was observed and reported accordingly.

In microscopic examination, centrifuging at 300 rpm for $10 \mathrm{~min}$, preparation of wet mount smear and gram stain was done for directly examination.

\section{Urine culturing and bacterial identification}

Urine specimen was used for culturing on sheep blood and MacConkey agar plates by calibrated loop of $1 \mu \mathrm{L}$ and incubated at $37{ }^{\circ} \mathrm{C}$ for $24 \mathrm{~h}$. Specimens with more than $10^{5}$ colony forming unit (CFU) per $\mathrm{ml}$ were considered as positive samples.

All isolates were identified morphologically and biochemically by standard laboratory procedures (Baird D. Staphylococcus).

\section{Antibiogram test}

Antimicrobial susceptibility test was performed according to "Kirby \& Bauer" method on MuellerHinton agar medium [17]. The agents used for antibiotic susceptibility testing of isolates are amikacin, ampicilin, cefixime, ceftazidime, ceftriaxone, cefuroxime, chloramphenicol, ciprofloxacin, cotrimaxazole, imipenem, nalidixic acid, nitrofurantoin, ofloxacin, tetracycline and trimethoprim. E. coli (ATCC 25922) was used as standard control strains.

\section{Statistical analysis}

Data collected in this study were evaluated by one-way analysis of variance (ANOVA) using SPSS 19. Differences at $p \leq 0.05$ were considered significant.

\section{RESULTS}

A total of 136 urinary specimens from different patients were obtained from 68 renal transplant and failure patients and 68 outpatients hospitalized in Tabriz Emam Reza hospital. 
They were 55 males $(40.44 \%)$ and 81 females $(59.55 \%)$ with different ages from 9 to 75 . Out of 136 bacterial isolates from the patients, the rate of $E$. coli $(98,72.05 \%)$ isolation was highest, as shown in Table 1.

Table 2 depicts the antibiotic susceptibility data for all the $E$. coli isolates in renal transplant and failure patients (group 1) and outpatients (group 2).

The antibiotic susceptibility pattern for $E$. coli isolated from group 1 showed the highest resistance to cefuroxime and ceftazidime (100 $\%)$ followed by ceftriaxone $(97.9 \%)$ and ciprofloxacin (95\%), while group 2 showed the highest resistance to ampicilin (95.83 \%) followed by cefuroxime $(91.66 \%)$ and ceftazidime (89.58\%). In order of efficacy nitrofurantoin was the most effective in groups 1 and 2 with $81.63 \%$ and $93.75 \%$, respectively (Table 2).

\section{DISCUSSION}

This study shows the prevalence and antibiotic susceptibility pattern of $E$. coli isolated from urinary tract infection in patients with renal failure disease and renal transplant recipients at Imam Reza hospital in Tabriz, Iran.

Antimicrobial resistance is a growing problem and a cause of great concern throughout the world [18]. Approximately 1 in 3 women will require antimicrobial treatment for a UTI before age 24 , and $40 \%$ to $50 \%$ of women will suffer from UTI during their lifetime [19]. In the last decades, the number of reports about appearance of bacteria with antibiotic resistance has increased all over the world [20]. This study, like others, shows clearly that there are significant geographic differences in the susceptibility of commonly used antimicrobials against UTIs [21]. Knowledge of antimicrobial resistance trends among isolates of uropathogens is essential to provide clinically appropriate and cost-effective therapy. Guidelines for the empirical treatment of patients with UTI suggest it is important to consider local resistance patterns of commonly isolated pathogens in selecting the antibiotic agents. This study provides an update on $E$. coli, the main cause of UTI in outpatients. Ampicillin or amoxicillin were once standard therapy for UTI, but resistance of $E$. coli to ampicillin has been on the increase in most regions of the world [22-24].

Table 1: Frequency of isolates in studied population

\begin{tabular}{lcccc}
\hline Microorganism & \multicolumn{2}{c}{$\begin{array}{c}\text { Renal failure and } \\
\text { transplant patients }\end{array}$} & \multicolumn{2}{c}{ Outpatients } \\
\cline { 2 - 5 } & No. & $\%$ & No. & $\%$ \\
\hline E. coli & 49 & 72.05 & 46 & 67.64 \\
Staphylococcus aureus & 5 & 7.35 & 3 & 4.41 \\
Serratia & 1 & 1.47 & 1 & 1.47 \\
Enterococcus & 3 & 4.41 & 4 & 5.88 \\
Klebsiella & 5 & 7.35 & 4 & 5.88 \\
Pseudomonas & 5 & 7.35 & 7 & 10.29 \\
Staphylococcus epidermidis & 0 & 0 & 3 & 4.41 \\
\hline
\end{tabular}

Table 2: Antibiotic sensitivity pattern of $E$. coli isolates

\begin{tabular}{lcccccc}
\hline \multirow{2}{*}{ Antibiotic } & \multirow{2}{*}{ Code } & Disk & \multicolumn{2}{c}{ Group 1 } & \multicolumn{2}{c}{ Group 2 } \\
\cline { 4 - 7 } & & $(\boldsymbol{\mu g})$ & Resistant (\%) & Sensitive (\%) & Resistant (\%) & Sensitive (\%) \\
\hline Ampicilin & AP & 10 & 87.75 & 12.24 & 95.83 & 4.16 \\
Cotrimaxazole & TS & 25 & 81.63 & 18.36 & 60.41 & 39.58 \\
Tetracycline & T & 30 & 85.71 & 14.28 & 54.16 & 45.83 \\
Nalidixic Acid & NA & 30 & 89.79 & 10.2 & 85.41 & 14.58 \\
Cefuroxime & CXM & 30 & 100 & 0 & 91.66 & 8.3 \\
Ceftriaxone & CRO & 30 & 97.9 & 2.04 & 64.58 & 35.41 \\
Imipenem & IMI & 10 & 20.4 & 79.59 & 10.41 & 89.58 \\
Nitrofurantoin & NI & 300 & 18.36 & 81.63 & 6.25 & 93.75 \\
Amikacin & AK & 30 & 32.65 & 67.34 & 25 & 75 \\
Chloramphenicol & C & 30 & 36.73 & 63.26 & 8.3 & 87.5 \\
Cefixime & CFM & 5 & 85.71 & 14.28 & 66.66 & 33.33 \\
Ceftazidime & CAZ & 30 & 100 & 0 & 89.58 & 10.41 \\
Ciprofloxacin & CIP & 5 & 95 & 4.08 & 27.08 & 72.91 \\
Trimethoprim & TM & 5 & 85.71 & 14.28 & 81.25 & 18.75 \\
Ofloxacin & OFX & 30 & 81.63 & 18.36 & 79.16 & 20.83 \\
\hline
\end{tabular}


The present study demonstrated that the prevalence of ampicillin resistance was 87.75 and $95.83 \%$ for renal failure and transplant patients and outpatients, respectively.

A urine specimen for culture obtained before the initiation of antimicrobial therapy confirms the diagnosis of UTI. The choice of antibiotics depends upon the causative organism and its local expected antibiotic susceptibility pattern. Comparisons of the findings of the present study with those of other recent similar studies indicate similarity.

Findings in this study are similar to those of previous studies for USA [21] and Iran [25]. Reports from developed and developing nations such as Turkey, Senegal, Brazil, Slovenia, Southern India and Australia are also consistent with the present findings [11,26-28].

The lack of sufficient data about bacterial resistance to the antimicrobial agents in developing countries, including Iran, may be responsible for the increasing emergence of multiple-drug resistance (MDR) [29].

\section{CONCLUSION}

Findings from this study demonstrate that nitrofurantoin and imipenem can be used as firstand second-line empirical treatments of pathogenic E. coli in Tabriz, Iran. However, this recommendation also requires careful and extensive monitoring at healthcare centers to avoid increase in resistance in these bacterial agents.

\section{ACKNOWLEDGEMENT}

The authors would like to acknowledge the staff of Department of Bacteriology and Virology, School of Medicine, Tabriz University of Medical Sciences for their technical support during the processing and analysis of samples.

\section{REFERENCES}

1. Umolu PI, Okoli EN, Izomoh IM. Antimicrobial susceptibility and Escherichia coli isolates obtained from different human clinical specimens in Lagos Nigeria. J Am Sci 2006; 2: 70-76.

2. Vila J, Simon $K$, Ruiz J, Horcajada JP, Velasco $M$, Barranco M, Moreno A, Mensa J. Are quinoloneresistant uropathogenic Escherichia coli less virulent? $\mathrm{J}$ Infect Dis 2002; 186: 1039-1042.
3. Svanborg C, Godaly G. Bacterial virulence in urinary tract infection. Infect Dis Clin North Am 1997; 11: 513529.

4. Kee T, Lu YM, Vathsala A. Spectrum of severe infections in an Asian renal transplant population. Transplant Proc 2004; 36: 2001-2003.

5. Haller $M$, Brandis $M$, Berner R. Antibiotic resistance of urinary tract pathogens and rationale for empirical intravenous therapy. Pediatr Nephrol 2004; 19(9): 982-986.

6. Jakobsson B, Berg U, Svensson L. Renal scarring after acute pyelonephritis. Arch Dis Child 1994; 70(2): 111115.

7. Taneja $N$, Chatterjee SS, Singh $M$, Singh S, Sharma M. Pediatric urinary tract infections in a tertiary care center from north India. Indian J Med Res 2010; 131: 101-105

8. Stamm WE, Norrby RS. Urinary tract infections: disease panorama and challenges. J Infect Dis 2001; 183: S1-S4

9. Foxman B. Epidemiology of urinary tract infections: incidence, morbidity, and economic costs. Dis Mon 2003; 49(2): 53-70.

10. Cambaz S, Peksen Y, Tevfi k, Sunter A, Leblebicioglu $H$, Sunbul M. Antibiotic prescribing and urinary tract infection. Int J Antimicrob Agents 2002; 20(6): 407411

11. Dromigny JA, Nabeth $P$, Juergens-Behr A, PerrierGrosClaude JD. Risk factors for antibiotic resistant Escherichia coli isolated from community-acquired urinary tract infections in Dakar, Senegal. J Antimicrob Chemother 2005; 56: 236-239.

12. Zhanel GG, Hisanaga TL, Laing NM, DeCorby MR, Nichol KA, Weshnoweski B, Johnson J, Noreddin A, Low DE, Karlowsky JA, Hoban DJ. Antibiotic resistance in Escherichia coli outpatient urinary isolates: results from the North American Urinary Tract infection Collaborative Alliance (NAUTICA). Int J Antimicrob Agents 2006; 27: 468-475

13. Kahlmeter G, An international survey of the antimicrobial susceptibility of pathogens from uncomplicated urinary tract infections: the ECO. SENS Project. J Antimicrob Chemother 2003; 51: 69-76

14. Andrade SS, Sader HS, Jones RN, Pereira AS, Pignatari $A C$, Gales $A C$. Increased resistance to fi rst-line agents among bacterial pathogens isolated from urinary tract infections in Latin America: time for local guidelines? Mem Inst Oswaldo Cruz, Rio de Laneiro, 2006; 101(7): 741-748

15. Hryniewicz K, Szczypa K, Sulikowska A, Jankowski K, Betlejewska K, Hryniewicz W. Antibiotic susceptibility of bacterial strains isolated from urinary tract infections in Poland. J Antimicrob Chemother 2001; 47(6): 773-780.

16. Nadia Gul, Talat Y. Mujahid, Samira Ahmad. Isolation, Identification and Antibiotic Resistance Profile of Indigenous Bacterial Isolates from Urinary Tract 
Infection Patients. Pak J Bio Sci 2004; 7(12): 2051 2054

17. Farshad $S$, Ranjbar $R$, Anvarinejad $M$, Shahidi MA, Hosseini M. Emergence of Multi Drug Resistant Strains of Eschetichia coli Isolated from Urinary Tract Infection. Open Conf Proc J. 2010; 1: 192-196.

18. Ghotaslou R, Yaghoubi A, Sharify S. Urinary Tract Infections in Hospitalized Patients during 2006 to 2009 in. J Cardiovasc Thorac Res 2010; 2(1): 39-42.

19. Foxman B. Epidemiology of urinary tract infections: incidence, morbidity, and economic costs. Am J Med 2002; 113: 5S-13S

20. Ranjbar R, Haghi-Ashtiani M, Jafari NJ, Abedini M. The prevalence and antimicrobial susceptibility of bacterial uropathogens isolated from pediatric patients. Iranian J Pub Health 2009; 38(2): 134-138.

21. Daza R, Gutierrez J, Piedrola G. Antibiotic susceptibility of bacterial strains isolated from patients with community-acquired urinary tract infections. Int $\mathrm{J}$ Antimicrob Agents 2001; 18(3): 211-215.

22. Dromigny JA, Nabeth $P$, Juergense $B A$, Gros-Claude JDP. Risk factors for antibiotic- resistant Escherichia coli isolated from community acquired urinary tract infection in Dakor, Senegal. J Antimicrob Chemother 2005; 33: 89-94.

23. Randrianirina $F$, Soares JL, Carod JF, Ratsima E, Thonnier V, Combe $P$, Grosjean $P$, Talarmin $A$. Antimicrobial resistance among uropathogens that cause community-acquired urinary tract infections in
Antananarivo, Madagascar. J Antimicrob Chemother, 2007; 59: 309-312

24. Uzunkovic-Kamberovic S. Antibiotic resistance of coliform organisms from community-acquired urinary tract infections in Zenica-Doboj Canton, Bosnia and Herzengovina. J Antimicrob Chemother 2006; 58: 344-348

25. Amin M, Mehdinejad M, Pourdangchi Z. Study of bacteria isolated from urinary tract infections and determination of their susceptibility to antibiotics. Jundishapur J Microbiol 2011; 2(3): 118-123.

26. Guidoni EBM, Berezin EN, Nigro S, Santiago NA, Benini $V$, Toporovski J. Antibiotic resistance patterns of pediatric community acquired urinary infection. Braz $J$ Infect Dis 2008; 12: 321-323.

27. Yuksel S, Ozturk B, Kavaz A, Ozcakar ZB, Acar B, Guriz $H$, Aysev D, Ekim M, Yalçınkaya F. Antibiotic resistance of urinary tract pathogens and evaluation of empirical treatment in Turkish children with urinary tract infection. Int J Antimicrob Agent 2006; 28: 413416.

28. Mehr SS, Powell CV, Curtis N. Cephalosporin resistant urinary tract infection in young children. $J$ Paediatr Child Health 2004; 40(1-2): 48-52.

29. Ebrahimzadeh MA, Mahdavee MR, Vahedi M. Antibiotic resistance in $E$. coli isolated from urine: A2-years study isolated from patient with urinary tract infections in Iran. J Cell Tissue Res 2005; 5(2): 445-448. 